\title{
The Relationship Between Autonomy-supporting Coaching and Interruption Intention: Verification of the Mediating Effect of Emotional Intelligence
}

\author{
Youngtaek $\mathrm{Oh}^{1}$
}

Affiliation: Department of Kinesiology, College Natural Science, Jeju National University Address: 102 Jejudaehak-ro, Jeju, Republic of Korea

Phone: +82-64-754-2273

Fax: +82-64-757-1752

E-mail: oyt0712@jejunu.ac.kr

\section{Conflict of interest}

The authors declare that they have no conflict of interest.

Each of the authors has read and concurs with the contact in the final manuscript.

"All authors read and approved the final version of the manuscript".

Address correspondence to Youngtaek Oh, Ph. D Department of Kinesiology, Jeju National University, Jeju 63243, South Korea. Email: oyt0712@jejuna.ac.kr

\begin{abstract}
Objective: Studies in Sports Psychology and Sociology have validated causality in team-sport athletes by using emotional intelligence as a variable. This study aimed to examine the causal relationship between the types of autonomy support coaching, emotional intelligence, and interruption intention as psychosocial variables among current taekwondo athletes in Korea.

Methods: In this study, 217 adult or university athletes registered in the Korea Taekwondo Association in 2020 were evaluated for the type of autonomy support coaching, emotional intelligence, and interruption intention.

Results: Autonomy support coaching recognized by taekwondo athletes has a negative and positive effect on interruption intention and emotional intelligence, respectively. Moreover, emotional intelligence has a negative effect on interruption intention. which revealed that autonomy support coaching has a negative effect on interruption intention through emotional intelligence.

Conclusions: Such outcomes can serve as a foundation for athletes to have the opportunity to participate in sports in a mature manner and promote positive changes in sports culture. In other words, the sensibility of the athletes can be harmoniously symmetry.
\end{abstract}

Keywords: Autonomy support coaching; Emotional intelligence; Interruption intention; Social competence, Symmetry 


\section{Introduction}

Emotional intelligence (EI) is an adaptive perceptual ability wherein a set of abilities (i.e., verbal and nonverbal) enable individuals to generate, recognize, express, understand, and evaluate their and others' emotions, which can direct thoughts and action that athletes use to successfully manage environmental demands and pressure. ${ }^{1-2}$ stated that people with high EI are better at evaluating and controlling their emotions. Therefore, they are more likely to maintain higher satisfaction in social life than those with low EI. For example, people with high EI are better at identifying frustration and stress. They are suitably flexible in controlling their emotions to reduce stress. They reported that because people with high EI can understand the cause of the stress and develop strategies and patience to manage with negative results, they are more resilient. On the other hand, people with low EI lack awareness regarding their feelings and the ability to cope when encountered with difficult situations, which aggravates stress and reduces their satisfaction in social life. $^{3}$

Anthropologists assert that the proper expression of emotions and awareness of other people's emotional expression are related to successful functions and effective leadership in society. ${ }^{4}$ In particular, EI capabilities, including transformational leadership, confidence, selfawareness, transparency, and empathy, are considered essential factors in conveying a vision for future. ${ }^{5-6}$ Based on this theoretical background, this paper investigates autonomy support coaching as an independent variable and interruption intention, which athletes may impulsively experience, as a dependent variable. According to the cognitive evaluation theory under the self-determination theory, ${ }^{7-8}$ autonomy support coaching recognizes players' thoughts and emotions in sports events; respects their individual initiatives, behavior regulation, and choices; and helps them participate in these events.

When an athlete truly "gives up" on their career because of personal psychological and socio-environmental factors, such as discomfort, stress, and exhaustion, experienced during athletic activities, it is referred to as interruption intention. Such interruption intention is engendered by various factors, such as socioeconomic status and stress and optimism, which interferes with their athletic and academic studies. ${ }^{9-10}$ Therefore, ${ }^{11}$ explained that future research is required to understand the cause of interruption intention among athletes and prevent it.

In summary, the leadership of a coach in sports field has a significant psychological and social impact on athletes. The use of positive feedback will foster a positive mindset among athletes, whereas negative feedback will arouse negative experiences, such as stress and exhaustion, for the athletes. If the athletes can understand and manage their and other's emotions, they can develop the ability to mitigate negative psychological effects by generating a positive attitude.

According to numerous scholars, people with high EI experience success in education, work, and life, abilities related to emotional intelligence, personality characteristics, and affective wellbeing. ${ }^{12-14}$ Moreover, they are reported to maintain cognitive and social functions, psychological wellbeing, effective leadership, and other actions and performances required in organizations. ${ }^{15-17}$ Therefore, this paper aims to validate the role of EI as a mediating variable on the relationship between autonomy support coaching and interruption intention of elite taekwondo athletes. To the best of our knowledge, this is the first study wherein the causal relationship between these variables is explored in taekwondo athletes.

If the results of this study are consequential, it can serve as a foundation for athletes to participate in sports in a more mature manner and thereby cultivate positive changes in future sports culture.

Accordingly, the purpose of this study is to control the relationship between interruption intention and autonomy support coaching recognized by taekwondo athletes with EI as a mediating variable. 


\section{Subjects}

\section{Methods}

The study included 217 adult and university taekwondo athletes, who were registered with the Korea Taekwondo Association in 2020. Nonprobabilistic purposive sampling was performed to select subjects. A total of 217 people were selected, with 149 male $(68.7 \%)$ and 68 female $(31.3 \%)$ athletes.

\section{Procedure}

Autonomy support coaching

The scale developed ${ }^{18}$ was used for autonomy support coaching. The subjects were asked to respond using a five-point Likert scale. From the scale, two questions that lacked commonality were eliminated through exploratory factor analysis, and one factor with seven questions was selected (Kaiser-Meyer-Olkin [KMO] measure $=.894$, Bartlett's test of sphericity test $\left.\chi^{2}=1128.168, d f=21, p<.001\right)$. Reliability coefficient evaluated using Cronbach's $\alpha$ was high with .92 . Confirmatory factor analysis revealed a relatively good fit index $\left(\chi^{2}=21.661, d f=11, p<.05, \mathrm{Q}=1.969\right.$, Bollen's Incremental Fit Index [IFI] $=.991$, Tucker-Lewis Index $[$ TLI $]=.982$, Comparative Fit Index $[\mathrm{CFI}]=.991$, Root Mean Square Error of Approximation [RMSEA] $=.067$ ).

\section{Emotional Intelligence}

The scale developed ${ }^{19}$ was used for EI. The questionnaire comprised 16 questions and measured responses on a seven-point Likert scale. One question lacking commonality was eliminated through exploratory factor analysis and four factors were selected (KMO measure $=.869$, Bartlett's test of sphericity test $\left.\chi^{2}=2149.130, d f=105, p<.001\right)$. Reliability coefficients for self-emotion, others' emotion, use of emotion, and regulation of emotion were $.86, .90, .86$, and .89 . Confirmatory factor analysis revealed a relatively good fit index $\left(\chi^{2}=263.320, d f=84, p<.001, \mathrm{Q}=3.135, \mathrm{IFI}=.916, \mathrm{TLI}=.893, \mathrm{CFI}=.915, \mathrm{RMSEA}=\right.$ $.099)$.

\section{Interruption intention}

For interruption intention, the scale created ${ }^{20}$ was used. This Korean version was based on that of ${ }^{21}$ wherein the concept of motivation, interruption intention, and negative attitude toward taekwondo were extracted from self-determination motivation. This scale comprises 10 questions, and the subjects were asked to respond using a five-point Likert scale. One question that lacked commonality was eliminated through exploratory factor analysis, and one factor with nine questions was selected (KMO measure $=.937$, Bartlett's test of sphericity $\left.\chi^{2}=1931.070, d f=36, p<.001\right)$. The reliability coefficient was .96 . Confirmatory factor analysis revealed a relatively good fit index $\left(\chi^{2}=57.348, d f=19, p<\right.$ $.001, \mathrm{Q}=3.018, \mathrm{IFI}=.980, \mathrm{TLI}=.962, \mathrm{CFI}=.980, \mathrm{RMSEA}=.097)$.

\section{Method of Analysis}

Data were collected by one researcher and seven research assistants between August and September 2020. Each team was approached in person, and the purpose of the study was explained in advance over the phone to the coaches of the adult and university taekwondo teams in Gyeonggi Province, Daegu Metropolitan City, Busan Metropolitan City, Seoul Metropolitan City, Jeollabuk-do Province, and Jeju Special Self-Governing Province. The questionnaire was distributed, the athletes were asked for consent, provided with detailed 
explanation, and requested to provide sincere responses. All participants provided written informed consent, and the study was approved by the Institutional Review Boards at Jeju National University(JJNU-IRB-2020-048).

The collected data were analyzed in accordance with the purpose of the study by using SPSS 18.0 and Amos 18.0 statistical programs. First, frequency analysis was performed. Second, the Cronbach's $\alpha$ values were calculated to validate the reliability of each measurement tool. Exploratory and confirmatory factor analyses were performed to construct validity. Third, Pearson product-moment correlation coefficients were calculated. Fourth, structural equation modeling was used to validate the mediating role of EI in the correlation between autonomy support coaching and interruption intention. For EI, subfactors were used as measurement variables. To construct variables for autonomy support coaching and interruption intention, three parcels (parcel: a suite of questions) were developed for each latent variable by applying the methods proposed by Russell, Kahn, Spoth, \& Altmaier. ${ }^{22}$ Factor loadings were then arranged in a high to low order by adding questions with the highest and lowest factor loadings. The questions were allocated to three parcels ensuring that the average of the factor loadings for each parcel were equal.

\section{Results \\ Result of Statistical and Correlation Analyses}

$<$ Table $1>$ presents the calculated average, standard deviation, skewness, kurtosis, and correlation coefficient of the variables extracted from exploratory factor analysis.

Table 1. Correlation coefficient between measurement variables

\begin{tabular}{|c|c|c|c|c|c|c|}
\hline Variable & A & B & $\mathrm{C}$ & D & $\mathrm{E}$ & $F$ \\
\hline $\begin{array}{l}\text { Autonomy support } \\
\text { coaching(A) }\end{array}$ & 1.00 & & & & & \\
\hline Selfemotion(B) & $291^{*}$ & 1.00 & & & & \\
\hline Others'emotion(C) & $373^{*}$ & $.562^{*}$ & 1.00 & & & \\
\hline Useofemotion(D) & $.423^{*}$ & $.563^{*}$ & $.446^{*}$ & 1.00 & & \\
\hline Regulation ofemotion(E) & $250^{*}$ & $.323^{*}$ & $.328^{*}$ & $.485^{\circ}$ & 1.00 & \\
\hline InterruptionIntention(F) & $-442^{*}$ & $-266^{*}$ & -187 & $-35^{*}$ & $-200^{\circ}$ & 1.00 \\
\hline $\mathrm{M}+\mathrm{SD}$ & $4.03 \pm 66$ & $4.83 \pm 88$ & $5.07 \pm 1.02$ & $4.96 \pm 1.03$ & $4.94+1.31$ & $2491 \pm .97$ \\
\hline Skewness & -23 & .17 & 22 & .01 & -31 & 31 \\
\hline \multirow[t]{2}{*}{ Kurtosis } & -53 & 59 & -.75 & .05 & 30 & -49 \\
\hline & & ${ }^{*} \mathrm{p}<.05$ & & & & \\
\hline
\end{tabular}

\section{Measurement Model Analysis}

The measurement model was validated to determine whether the variables in the model appropriately measured the latent variables. The analysis revealed that the goodness of the measurement model was appropriate $\left(\chi^{2}=58.729, d f=32, p<.01, \mathrm{Q}=1.835\right.$, Bentler-Bonett Normed Fit Index $[\mathrm{NFI}]=.953, \mathrm{RFI}=.934, \mathrm{IFI}=.978, \mathrm{TLI}=.969, \mathrm{CFI}=.978, \mathrm{RMSEA}=.062$ ). Factor loadings for the latent variable of each of the 10 variables were all significant as $p<.001$ $<$ Figure $1>$. 


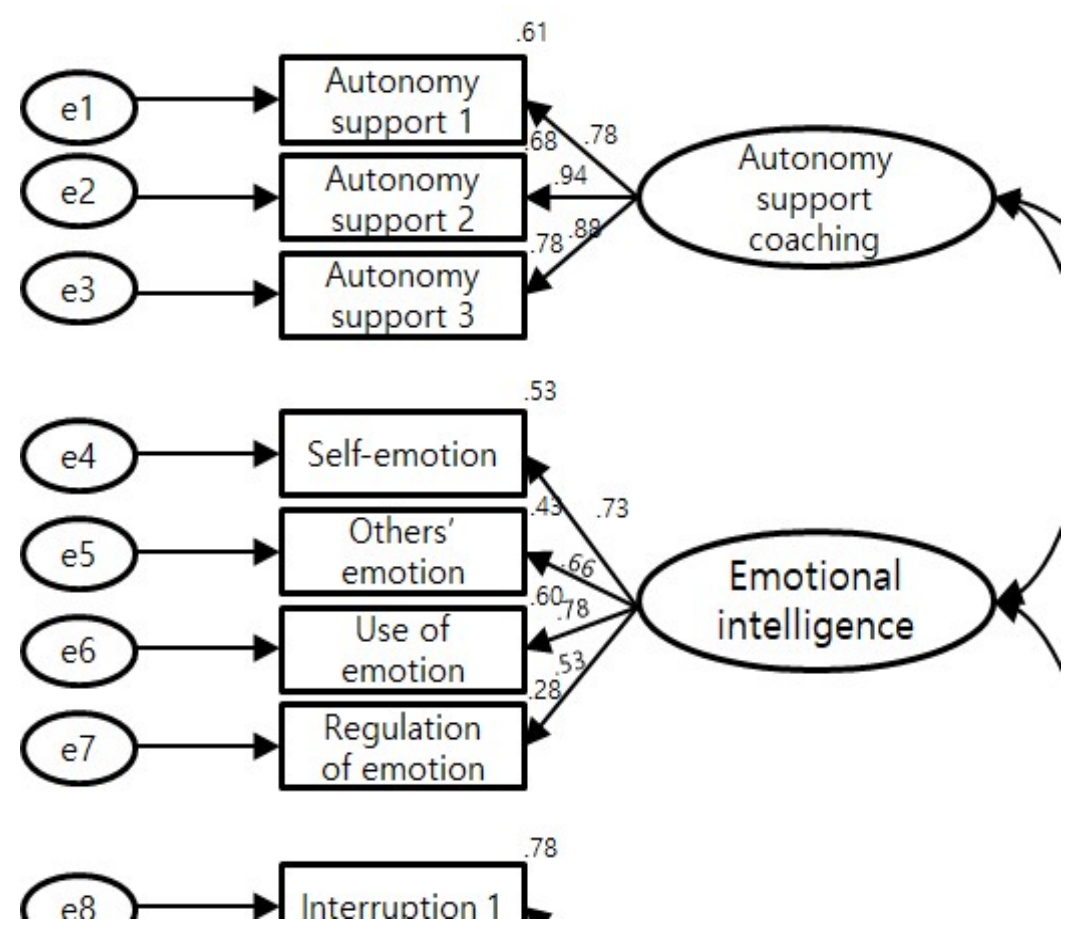

Fig 1. Analysis of measurement model among variables

\section{Validation of Structural Model}

A structural model was constructed to examine the mediating effect of EI in the relationship between autonomy support coaching and interruption intention. Following the verification of the mediating effect proposed, ${ }^{23}$ autonomy support coaching (the independent variable) had a direct, significant, and negative effect $(-)$ on interruption intention (the dependent variable) $(\beta=-.407, p<$ $.001)$.

Emotional intelligence, a mediating variable, was then inserted into the model, and a structural model was constructed wherein the direct path between autonomy support coaching (a predictor variable) and Interruption intention (an outcome variable) was eliminated. The validation results revealed that the goodness of the complete mediation model was excellent $\left(\chi^{2}=72.998, d f=\right.$ $33, p<.001, \mathrm{Q}=2.212, \mathrm{NFI}=.942, \mathrm{RFI}=.921, \mathrm{IFI}=.967, \mathrm{TLI}=.955, \mathrm{CFI}=.967, \mathrm{RMSEA}=$ .075). Autonomy support coaching, the predictor variable, validated the partial mediation model including the direct path to interruption intention which is the dependent variable. The validation results revealed that the partial mediation model is appropriate for the data $\left(\chi^{2}=58.729, d f=32, p<\right.$ $.001, \mathrm{Q}=1.835, \mathrm{NFI}=.953, \mathrm{RFI}=.934, \mathrm{IFI}=.978, \mathrm{TLI}=.969, \mathrm{CFI}=.978, \mathrm{RMSEA}=.062)$. The path coefficients of the model were significant $(p<.001)$. The $\chi^{2}$ difference test was conducted to determine the difference between the fitness of partial and full mediation models, which revealed a significant difference $\left(\triangle \chi^{2}=14.269, d f=1, p<.001\right)$. Therefore, the partial mediation model was selected as the final model as show in $<$ Figure $2>$, $<$ Table $2>$. Reveals that autonomy support coaching had a significant negative effect $(-)$ on interruption intention $(\beta=-.302, p<.001)$ and a significant positive effect $(+)$ on EI $(\beta=.449, p<.001)$. EI had a significant negative effect $(-)$ on interruption intention $(\beta=-.236, p<.01)$. Furthermore, the mediating effect on EI was analyzed. The result of indirect effect analysis was -.139 , with confidence interval between -.256 and -.055 excluding 0 . It revealed that the indirect effect was significant at a .05 level. 


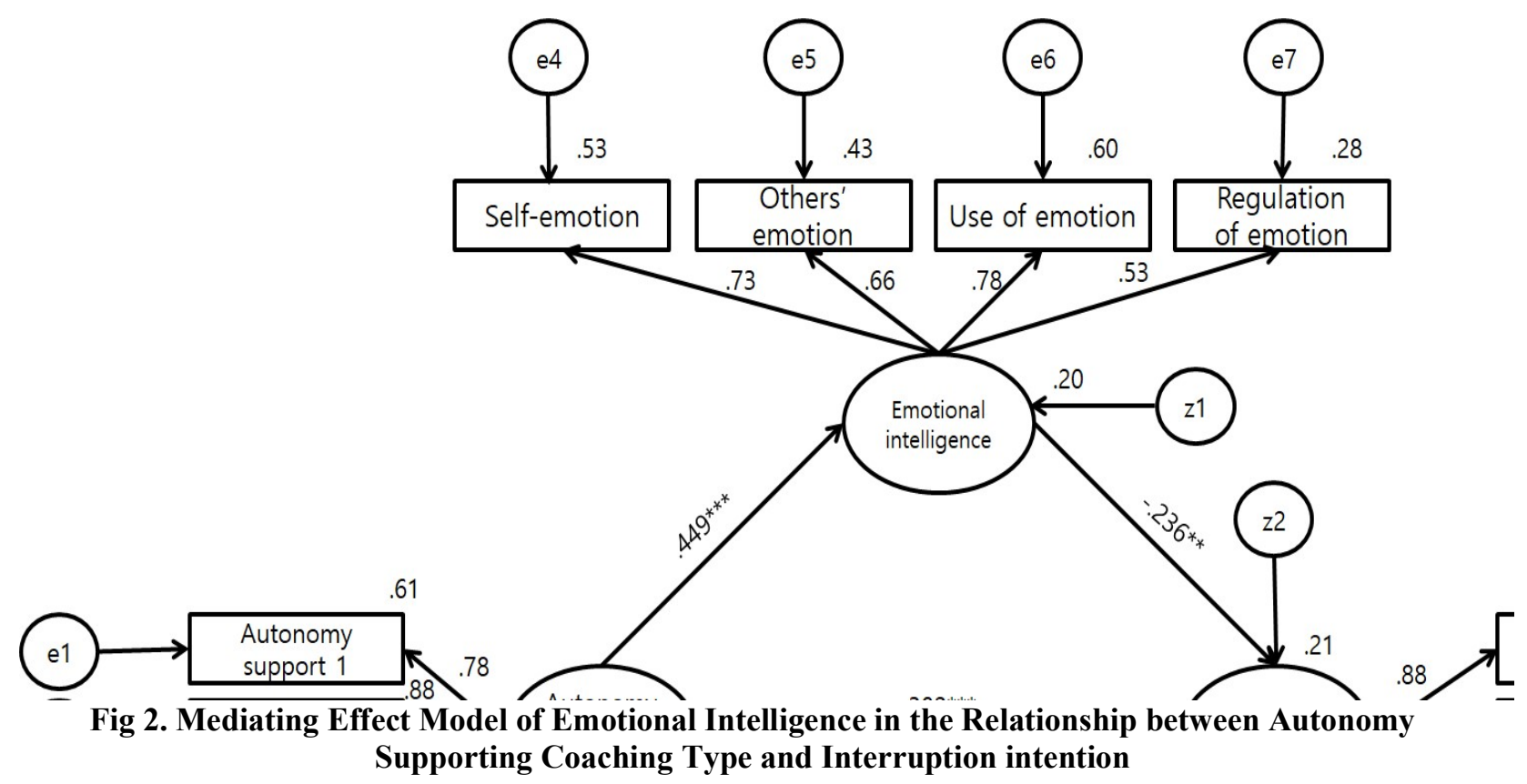

Table 2. Estimated value of path coefficient of measurement model

\begin{tabular}{|c|c|c|c|c|c|c|}
\hline Route & Estimate & S.E & C.R & $p$ & SRW & SMC \\
\hline Emotional intelligence $\leftarrow$ Autonomy support coaching & .398 & .072 & 5.550 & .001 & .449 & 202 \\
\hline Intemuptionintention $\lessdot$ Autonomy support coaching & -398 & .104 & -3.809 & .001 & -302 & 211 \\
\hline Intemptionintention - Emotional intelligence & -350 & .127 & -2.747 & .01 & -236 & 211 \\
\hline Autonomy support coaching $8 \leftarrow$ Autonomy support coaching & 1.000 & & & & .882 & .835 \\
\hline Autonomy support coaching $7 \leftarrow$ Autonomy support coaching & 1.070 & .059 & 18.132 & .000 & .936 & .765 \\
\hline Autonomy support coaching $6 \leftarrow$ Autonomy support coaching & .846 & .059 & 14.284 & .000 & .779 & .782 \\
\hline Selfemotion $\leftarrow$ Emotional intelligence & 1.000 & & & & .731 & 282 \\
\hline Others'emotion -Emotional intelligence & 1.052 & .127 & 8275 & .000 & .658 & .602 \\
\hline Useofemotion $\leftarrow$ Emotional intelligence & 1.254 & .137 & 9.154 & .000 & .776 & .434 \\
\hline Regulation ofemotion -Emotional intelligence & 1.086 & .159 & 6.824 & .000 & .531 & .534 \\
\hline Interuptionintention $6 \leftarrow$ - Intemptionintention & 1.000 & & & & .884 & .607 \\
\hline Intemuptionintention 7 -Intemuptionintention & 1.013 & .058 & 17.605 & .000 & .874 & .876 \\
\hline Intemuptionintention8 - Intemuptionintention & 1.096 & .058 & 18.778 & .000 & .914 & .777 \\
\hline
\end{tabular}

\section{Discussion}

EI is one of the most crucial attributes in sports. It can contribute to the important interpersonal relationship between coaches and athletes concerning motivation and performance. ${ }^{24}$ In particular, EI, aids in accurate recognition of emotions, can help understand interpersonal relationships and emotions of others, thereby allowing coaches to infer and respond appropriately to athletes' emotions and intentions. ${ }^{25}$ Athletes are emotionally stable and can intentionally express their emotions. ${ }^{26} \mathrm{EI}$ is associated with performance, stress response, and psychological skills. However, few studies have investigated its association with athletic coaching. ${ }^{27}$ Therefore, this study aimed to validate the mediating role of EI in the relationship between types of coaching and interruption intention in sports. As the first research involving taekwondo athletes, it can contribute significantly to the development of Sports Psychology and Sociology. The results of this study can be interpreted as follows.

First, autonomy support coaching had a significant negative effect (-) on interruption intention. The results support the findings of Jesesaar ${ }^{28}$ by showing that autonomy support from coaches has a significant positive effect $(+)$ on the intrinsic motivation, which is the driving force of 
the athlete's persistence in sports. Autonomy support provided by teachers or coaches has a positive effect on basic psychological requirements and intentional physical activities in the educational and athletic contexts based on the self-determination theory, which indirectly supports this study. That is, active support and positive feedback from coaches have been shown to discourage athletes to give up on sports and increase their will to exercise and participate more actively and enthusiastically. ${ }^{29-33}$

Autonomy support coaching had a significant positive effect $(+)$ on EI. Chan, \& Mallett ${ }^{34}$ reported that the effective coaching ability of a leader improves with high EI. ${ }^{35}$ conducted structural equation modeling on 323 basketball coaches and found a close relation among EI, coaching effectiveness, and leadership. Therefore, coaches can help athletes grow by providing the opportunity for image training and respect their opponents by providing guidance for tactics and chances to understand and analyze the tactics.

In addition, EI had a significant negative effect (-) on interruption intention. Research ${ }^{36}$ showed that EI has a significant negative effect $(-)$ on behavioral patterns, thus indirectly supporting this study. Although the lack of the direct validation of the relation between EI and interruption intention limits comparison and analysis in previous studies, this study suggests that EI is an antecedent to persistent participation in sports and thus reduces the desire of interruption intention.

Finally, the mediating effect of EI reduces interruption intention as autonomy support coaching significantly and negatively affected (-) interruption intention by mediating the relationship between autonomy support coaching and EI. EI had significant negative effect (-) on interruption intention in a study by Schlechter, ${ }^{37}$ which supports the results of this study. It supports the research in this study because interruption intention was reduced with increasing trust and faith. EI indicates the inner tendency of a person to consider and respect others and the ability to overcome difficult processes in sports. These aspects are necessary attributes for young teenager athletes who have just started out.

In summary, athletes tend experience difficulty in communicating their opinions to their coaches despite their close relationship in the sports field. This position can be understood because a coaching practice methodology that was used to guide athletes involves coercive guidance. However, new coaches have a different attitude. They aim to communicate with the athletes to improve their technical skills and empathy. The ability to understand and empathize with other people's feelings varies depending on the individual's personality. Therefore, comfort, information, and choices from the coaches to the athletes can contribute to the reduction of interruption intension and thereby motivate the athletes to devote themselves to training with their teams.

If the active use of autonomy support by the athletic coaches encourages the athletes to think, sympathize, and care for others, the athletes will be able to participate in the training with a more mature attitude. Various studies on EI have been conducted on athletes in team sports, including soccer and basketball. ${ }^{38-39}$ However, to the best of our knowledge, this is the first study to produce meaningful results for the athletes of taekwondo, which is a competitive sport. Therefore, this study is expected induce a profound change and have a positive impact on the coach-athlete relationship and sports culture in the future.

\section{Conalusion and a proposal}

This study aimed to verify the mediating effect of EI in the relationship between the types of autonomy support coaching perceived by university and adult taekwondo athletes and interruption intention in sports. The study included 217 adult and university taekwondo athletes who were registered with the Korea Taekwondo Association in 2020. The following conclusions were obtained. First, autonomy support coaching had a significant negative effect $(-)$ on interruption intention. Second, autonomy support coaching had a significant positive effect $(+)$ on 
EI. Third, EI had a significant negative effect (-) on interruption intention. Fourth, autonomy support coaching had significant negative effect (-) on interruption intention through EI.

This study found that EI is crucial as a mediating variable for elite university and adult taekwondo athletes. This study is the first research to evaluate the taekwondo athletes' perceived ability, expressiveness, and empathy for others. Second, further research is required to verify that these results can be reproduced in teenage athletes. Third, EI is one of the most active research topics in the field of business administration. Therefore, it is recommended that more studies be conducted in the field of physical education and more attention be provided to the development of EI among athletes, which can subsequently encourage them to participate in sports activities.

\section{References}

1. Van Rooy, D. L., \& Viswesvaran, C. Emotional intelligence: A meta-analytic investigation of predictive validity and nomological net. Journal of vocational Behavior. 2004;65(1):71-95.

2. Cooper, R. K., \& Sawaf, A. C. Executive EQ: Emotional intelligence in leadership and organization (No. 658.409 C7841c Ej. 1 000003). GROSSET;1997.

3. Shimazu, A., Shimazu, M., \& Odahara, T. Job control and social support as coping resources in job satisfaction. Psychological Reports. 2004; 94(2):449-56.

4. Boehm, C. Hierarchy in the forest: The evolution of egalitarian behavior. MA: Harvard University Press; 1999.

5. Daus, C. S., \& Ashkanasy, N. M. The case for the ability-based model of emotional intelligence in organizational behavior. Journal of Organizational behavior. 2005;26(4):453-66.

6. Goleman, D., Boyatzis, R. E., \& McKee, A. The new leaders: Transforming the art of leadership into the science of results. academia; 2002.

7. Deci, E. L., \& Ryan, R. M. The support of autonomy and the control of behavior. Journal of personality and social psychology. 1987;53(6):1024.

8. Deci, E. L., \& Ryan, R. M. Intrinsic motivation and self-determination in human behavior. NY: Plenum Press; 1985.

9. Bergeron, J., Chouinard, R., \& Janosz, M. The Impact of Teacher-Student Relationships and Achievement Motivation on Students' Intentions to Dropout According to Socio-Economic Status. Online Submission; 2011.

10. Eicher, V., Staerklé, C., \& Clémence, A. I want to quit education: A longitudinal study of stress and optimism as predictors of school dropout intention. Journal of Adolescence. 2014;37(7):1021-30.

11. Gardner, L. A., Magee, C. A., \& Vella, S. A. Enjoyment and behavioral intention predict organized youth sport participation and dropout. Journal of Physical Activity and Health. 2017;14(11):861-5.

12. Goleman, D. Emotional intelligence. NY: England; 1995.

13. Ciarrochi, J. V., Chan, A. Y., \& Caputi, P. A critical evaluation of the emotional intelligence construct. Personality and Individual differences. 2000;28(3):539-61.

14. Schutte, N. S., \& Malouff, J. M. Measuring emotional intelligence and related constructs. Edwin Mellen Press;

1999.

15. Van Rooy, D. L., Viswesvaran, C., \& Pluta, P. An evaluation of construct validity: what is this thing called emotional intelligence?. Human Performance. 2005;18(4):445-62.

16. Brackett, M. A., \& Mayer, J. D. Convergent, discriminant, and incremental validity of competing measures of emotional intelligence. Personality and social psychology bulletin. 2003;29(9):1147-58.

17. O'Boyle Jr, E. H., Humphrey, R. H., Pollack, J. M., Hawver, T. H., \& Story, P. A. The relation between emotional intelligence and job performance: A meta-analysis. Journal of Organizational Behavior. 2011;32(5):788-818.

18. Williams, G. C., \& Deci, E. L. Internalization of biopsychosocial values by medical students: a test of selfdetermination theory. Journal of personality and social psychology. 1996;70(4):767.

19. Wong, C. S., \& Law, K. S. The effects of leader and follower emotional intelligence on performance and attitude: An exploratory study. The leadership quarterly. 2002;13(3):243-74.

20. Park, D. H., \& Oh, Y. T. Kim. SU, In, SJ, \& Yang, M. H. Relationship between perceived achievement stress, athlete engagement, and dropout intention among kumdo athletes: Moderated mediation effect of parental social support. The Journal of Korean Alliance of Martial Arts. 2017;19(1):49-65.

21. Ryan, R. M., \& Deci, E. L. Self-determination theory and the facilitation of intrinsic motivation, social development, and well-being. American Psychologist. 2000;55(1):68.

22. Russell, D. W., Kahn, J. H., Spoth, R., \& Altmaier, E. M. Analyzing data from experimental studies: A latent variable structural equation modeling approach. Journal of counseling psychology. 1998;45(1):18. 
23. Holmbeck, G. N. (1997). Toward terminological, conceptual, and statistical clarity in the study of mediators and moderators: Examples from the child-clinical and pediatric psychology literatures. Journal of consulting and clinical psychology. 1997;65(4): 599-610.

24. O'neil, P. V. Advanced engineering mathematics. Cengage learning; 2011.

25. Lorimer, R. The development of empathic accuracy in sports coaches. Journal of Sport Psychology in Action. 2013;4:26-33.

26. Becker, A. It's not what they do, it's how they do it: Athlete experiences of great coaching. International Journal of Sports Science and Coaching. 2009;4(1):93-119.

27. Laborde, S., Dosseville, F., \& Allen, M. S. Emotional intelligence in sport and exercise: A systematic review. Scandinavian Journal of Medicine and Science in Sports. 2016;26:862-74.

28. Jõesaar, $H$. The effects of perceived peer motivational climate, autonomy support from coach, basic need satisfaction, and intrinsic motivation on persistence in sport (Doctoral dissertation TARTU UNIVERSITY PRESS); 2012.

29. Chatzisarantis, N. L., \& Hagger, M. S. Effects of an intervention based on self-determination theory on selfreported leisure-time physical activity participation. Psychology and Health. 2009;24(1):29-48.

30. Standage, M., \& Gillison, F. Students' motivational responses toward school physical education and their relationship to general self-esteem and health-related quality of life. Psychology of Sport and exercise. 2007;8(5):704-21.

31. Amorose, A. J., \& Anderson-Butcher, D. Autonomy-supportive coaching and self-determined motivation in high school and college athletes: A test of self-determination theory. Psychology of sport and exercise. 2007;8(5):654-70.

32. Deci, E. L., \& Ryan, R. M. The support of autonomy and the control of behavior. Journal of personality and social psychology. 1987;53(6):1024.

33. Almagro, B. J., Sáenz-López, P., \& Moreno, J. A. Prediction of sport adherence through the influence of autonomy-supportive coaching among Spanish adolescent athletes. Journal of sports science \& medicine. 2010;9(1):8.

34. Chan, J. T., \& Mallett, C. J. The value of emotional intelligence for high performance coaching. International Journal of Sports Science \& Coaching. 2011;6(3):315-28.

35. Hwang, S., Feltz, D. L., \& Lee, J. D. Emotional intelligence in coaching: Mediation effect of coaching efficacy on the relationship between emotional intelligence and leadership style. International Journal of Sport and Exercise Psychology. 2013;11(3):292-306.

36. Teques, P., Duarte, D. F., \& Viana, J. L. Coaches' emotional intelligence and reactive behaviors in soccer matches: Mediating effects of coach efficacy beliefs. Frontiers in psychology. 2019;10:1629.

37. Schlechter, A. F. The influence of transformational leadership, emotional intelligence, trust, meaning and intention to quit on organisational citizenship behaviour (Doctoral dissertation, Stellenbosch: University of Stellenbosch); 2005.

38. Rutkowska, K., \& Bergier, J. Psychological gender and emotional intelligence in youth female soccer players. Journal of human kinetics. 2015;47(1):285-91.

39. Ajilchi, B., Amini, H. R., Ardakani, Z. P., Zadeh, M. M., \& Kisely, S. Applying mindfulness training to enhance the mental toughness and emotional intelligence of amateur basketball players. Australasian Psychiatry. 2019;27(3):291-96. 